\title{
Naturaleza y libertad en Spinoza
}

\author{
Spinoza's Nature and Freedom
}

\author{
AURELIO SAINZ PEZONAGA \\ Universidad de Castilla la Mancha
}

Recibido: 15/04/2020 Aceptado:22/05/2020

\section{RESUMEN}

En la filosofía de Spinoza, la libertad va unida a la causalidad necesaria y ésta es una propiedad tanto de Dios en cuanto naturaleza absoluta como de las infinitas cosas singulares. El artículo parte de esta teoría de la libertad para exponer que, gracias a ella, Spinoza puede defender la historicidad radical de los modos finitos, lo que incluye una comprensión del ser como causa y de la causa como inmanencia de Dios en las cosas y de las cosas en su interdeterminación. Spinoza nos alienta a entendernos, a la vez, como causas adecuadas y causas parciales de nuestra experiencia.

\section{PALABRAS CLAVE \\ SPINOZA, LIBERTAD, NATURALEZA, NECESIDAD, HISTORICIDAD, MONARQUÍA ONTOLÓGICA, INMANENCIA}

\begin{abstract}
In Spinoza's philosophy, freedom is linked to necessary causality and this in turn is a feature of both God as absolute nature and of the infinite singular things. The article starts from this theory of freedom to explain that, thanks to it, Spinoza can defend the radical historicity of finite modes, which includes the comprehension of being as cause and of cause as the immanence of God in things and of things in their interdetermination. Spinoza encourages us to understand ourselves as both adequate causes and partial causes of our experience.
\end{abstract}

KEYWORDS

SPINOZA, FREEDOM, NATURE, NECESSITY, HISTORICITY, ONTOLOGICAL MONARCHY, IMMANENCE

(C) Contrastes. Revista Internacional de Filosofía, vol. XXVI Nº1 (2021), pp. 65-82. ISSN: 1136-4076

Departamento de Filosofía, Universidad de Málaga, Facultad de Filosofía y Letras

Campus de Teatinos, E-29071 Málaga (España) 
Podemos Pensar La ONTOlogía de Spinoza como una construcción teórica que busca taponar cualquier resquicio por el que pudiera colarse la indeterminación en el mundo. Excluye tanto la indeterminación de la primera causa, la voluntad libre de Dios o del ser humano, como la indeterminación de la serie infinita de causas y efectos, pues Dios se expresa en cada una de las conexiones de la infinita trama causal. Spinoza produce así una original concepción de la necesidad y, en consecuencia, de la libertad. La necesidad ya no es sinónimo de constricción, de obstáculo o de bloqueo, sino de autoafirmación y autodespliegue de la propia potencia. En Dios, en la necesidad absoluta de la urdimbre infinita de lo existente, la autoafirmación y el autodespliegue son igualmente absolutos. Y, por esa razón, Dios es enteramente libre, pues existe en virtud de la sola necesidad de su naturaleza y es determinado por sí solo a obrar (E 1D7). ${ }^{1}$

La libertad-necesidad de las cosas singulares aparece en la Ética en dos tiempos. La primera vez la encontramos en la proposición 29 de la Parte I: «En la naturaleza no hay nada contingente, sino que, en virtud de la necesidad de la naturaleza divina, todo está determinado a existir y obrar de cierta manera». En la proposición 7 de la Parte III, donde Spinoza identifica la esencia y la potencia de cada cosa (justo después de haber demostrado el conatus), como consecuencia de este «in rerum natura nullum datur contingens», deduce que las cosas no pueden más que aquello que necesariamente se sigue de su naturaleza determinada. Si la naturaleza de las cosas es absolutamente necesaria, lo que de ella se siga, esto es, lo que las cosas puedan, será necesario en el mismo grado. La esencia y la potencia de una cosa son absolutamente necesarias: el universo en su totalidad se expresa en ellas haciendo que perseveren en la existencia. Y la proposición 36 de la Parte I refuerza, completamente ya, esta tesis: ser es poder: no existe nada de cuya naturaleza no se siga algún

1 También Ep 56: 259. Citaré las referencias a la Ética (E) de Spinoza comenzando siempre por el número de la parte correspondiente. Luego, Pr: Praefatio; Ap: Appendix; P: Propositio, seguida del número de la proposición; también van seguidas de su número C: Corollarium, $\mathrm{S}$. Scholium, Ax: Axioma, D: Definitio, L: Lema, Pos: Postulatum y C: Caput. D después de P y número: Demonstratio; E: Explicatio. Cuando lo considere útil, añadiré detrás de dos puntos la página de la edición de Gebhardt sin aludir al volumen, que en este caso es el segundo. Excepto para mens, que vierto por «mente», recojo la traducción de Vidal Peña (Spinoza 1980). El Tratado breve $(\mathrm{KV})$ lo referencio en el siguiente orden: libro, capítulo, parágrafo. El Tratado teológico-político (TTP) lo cito por el número del capítulo y, separada por dos puntos, la página de la edición de Gebhardt sin aludir al volumen, que en este caso es el tercero. Pr: Praefatio. Las referencias al Tratado político (TP) las menciono por el número del capítulo y, separado por barra inclinada, el número del artículo. Y cito la Correspondencia (Ep) por el número de carta y, separada por dos puntos, página de la edición de Gebhardt sin aludir al volumen, que en este caso es el cuarto. 
efecto. Necesariamente, todo lo que existe, en tanto que existe de una manera determinada, tiene una determinada potencia. La potencia se despliega, necesariamente, en virtud de la naturaleza de la cosa. Y en esa necesidad, que es una necesidad absoluta, está la libertad de cada cosa singular: su potencia, enteramente suya, su esencia.

Ser libre y ser absolutamente necesario coincide tanto en Dios como en sus modos finitos. La diferencia fundamental es que Dios (sustancia que consta de infinitos atributos) es causa sui, esto es, es causa que no interactúa. Las cosas singulares, por el contrario, son causas adecuadas (de su naturaleza necesariamente se sigue algún efecto), pero también causas parciales (interactúan con otros individuos para producir conjuntamente un efecto). Por ello, sobre las cosas singulares cabe una doble perspectiva, una mirada de doble alcance, que no cabe sobre Dios. Una cosa singular puede pensarse como todo o causa adecuada (si se articula la concurrencia de individuos que necesariamente la producen) y como parte o causa parcial (si se deduce el efecto que necesariamente se sigue de su naturaleza y se pone en relación activa con la naturaleza de otras cosas).

Las cosas singulares se definen entonces por el doble nivel de complejidad (Balibar 2018, p. 221). Pero este implica una diferencia inserta en la propia esencia de la cosa: una diferencia entre su condición de causa adecuada y su condición de causa parcial (Ibid., p. 209). El doble nivel de complejidad implica así mismo una diferencia no sólo entre Dios y las cosas singulares, sino en su modo de causalidad. Parecería que la diferencia consiste en que Dios es causa adecuada mientras que las cosas singulares son, a un tiempo, causa adecuada y causa parcial. Pero ser sólo causa adecuada quiere decir sobre todo que Dios no es una cosa. $\mathrm{O}$, más en concreto, Dios no es una cosa entre cosas, no es una causa entre causas, que es el único modo de ser cosa en la filosofía de Spinoza. En Spinoza, la sustancia no es una cosa: es una acción sin rastro de pasión, esto es, sin sub-jectum: la potencia de Dios no es otra cosa que la esencia actuante de Dios (E 3P3S). Es absoluta necesidad, o sea, absoluta libertad.

Desde esta óptica, la filosofía de Spinoza ha de entenderse como inmediatamente práctica. Su filosofía es ya actividad ética y política, práctica afectiva: lucha contra la creencia en la voluntad libre y contra la concepción de la soberanía divina y de la desigualdad ontológicamente legitimada, esfuerzo por aumentar la propia potencia y la de los demás, por estar alegre y amar indefinidamente (Macherey 1998, p. 21 y Fernández García 1997, pp. 132$138)^{2}$

2 Véase, en general, todo el artículo de Eugenio Fernández (pp. 121-151) para una explicación imprescindible de la libera necessitas de Spinoza y sus consecuencias para la ética 


\section{LA HISTORICIDAD RADICAL}

Después de haber establecido en la proposición 29 la necesidad absoluta y específica de todas las determinaciones de todas las cosas singulares en su conexión infinita, Spinoza se preocupa, desde la proposición 30 a la 35, por demostrar con todo detalle la imposibilidad de concebir a Dios como algo separado de esa conexión infinita y su absoluta necesidad. Esa separación podría seguirse, en efecto, de que entendiéramos el mundo como resultado de una decisión de Dios, pensada y querida por Dios. Las proposiciones 30 a 33 cierran toda vía que pudiera querer entender que Dios piensa y quiere el mundo antes de causarlo. El entendimiento y la voluntad se incluyen dentro de la naturaleza naturada, no son naturaleza naturante. Dios no es sino causalidad y necesidad absolutas.

En todas estas proposiciones, Spinoza hace uso de la distinción entre lo absoluto: la sustancia y sus atributos, la naturaleza naturante; y lo derivado: los modos infinitos y finitos, naturaleza naturada.

Si aceptamos que no existe nada fuera de la interdeterminación infinita de las cosas singulares, hay que pensar lo absoluto como esa misma interdeterminación en cuanto se sostiene por sí misma en bloque, sin relación a ninguna otra cosa (pues no hay otra cosa) en el ser y en su conocimiento. Es el hacer-ser o la naturaleza o la necesidad o la potencia absoluta y entera que se expresa en cada determinación singular. Esto es lo que Spinoza llama con toda coherencia «sustancia».

Nada hay más allá de la infinita interdeterminación de las cosas singulares. Dios es el concepto de esta condición en la que algo es sin otro. El concepto de Dios indica que esta interdeterminación infinita satura completamente las posibilidades de causalidad, esto es, que no hay un otro susceptible de producirla, limitarla o determinarla. La interdeterminación infinita no puede ser producida por otro y por ello, si es, sólo le cabe ser necesariamente, y ser necesariamente sin exterior («absolutamente infinito» es el concepto que utiliza Spinoza). La saturación de lo posible equivale a su cancelación y ésta, a la necesidad absoluta de la interdeterminación infinita.

La equiparación entre realidad y perfección que Spinoza sostiene en el escolio 2 de la proposición 33 contra los defensores de una voluntad absoluta de Dios no es sino un aspecto más de esta concepción de la sustancia. No hay una ley por encima (por debajo, anterior o exterior) de los acontecimientos singulares. Los acontecimientos singulares son la ley. Y ésta es la verdad eterna que es necesario conocer: el acontecer es todo. La ley, o mucho mejor, las infinitas leyes están en los infinitos aconteceres mismos, en la infinita

y la política, con la que mi exposición coincide en muchos aspectos. 
producción de «hechos» a partir de otros «hechos» (Macherey 2011, pp. 86116).

Mejor, entonces, que hablar de «contingencia radical», como hace Vittorio Morfino (2012, p. 39), podríamos referimos a una «facticidad radical» en la medida en que la condición de lo «hecho», de lo producido por otro «hecho» o lo acontecido es la que define a las infinitas cosas singulares en su esencia, en su potencia, en su existencia y en su determinación a obrar. Pero, para evitar el carácter pasivo que se atribuye al «hecho» en la tradición empirista, quizás sea mejor plantear una «historicidad radical», tanto en el sentido de que lo «hecho» es también lo que produce otros «hechos» hasta el infinito -lo «hecho» es causa y efecto-, como en el de que la esfera de la investigación sobre cualquier «hecho» sólo puede estar compuesta de otros «hechos», como explica Spinoza en el capítulo VII del TTP, precisamente porque esos otros «hechos» son los que lo han producido, porque su acontecer se explica por la conexión entre otros múltiples «hechos».

Poco avanzaríamos, no obstante, si la historicidad radical la entendiéramos como hace, por ejemplo, Ernesto Laclau a partir de una visión culturalista e historicista del mundo y de la noción de contingencia entendida como indeterminación (2000, pp. 20 y 52). Spinoza habla de contingencia en dos sentidos. Su investigación le conduce de uno a otro, en concreto de $\mathrm{E}$ 1P29 a E 1P33S1 y las definiciones de la Parte IV. En un primer sentido (E 1P29), contingencia es sinónimo de indeterminación. Necesidad se opone a contingencia en la misma medida en que determinación se opone a indeterminación. Determinación es lo que hay. Indeterminación es lo que no hay. En un segundo sentido (E 1P33S1), dado que la indeterminación no es, cuando se presenta sólo puede entenderse como ignorancia. Primero, contingencia es indeterminación, luego contingencia es ignorancia. La ignorancia se opone al entender (intelligere), porque este es conocimiento de lo necesario. Cuando no se entienden, las cosas aparecen como contingentes o posibles, como efecto de la ignorancia. Pero las dos oposiciones no son simétricas. Determinación / indeterminación se excluyen mutuamente en términos absolutos, pero entendimiento e ignorancia, aunque son opuestos, conviven necesariamente en las vidas humanas. Cierto grado de ignorancia es inevitable, necesaria, no contingente, en los seres finitos como los humanos que no podemos escapar completamente a las pasiones.

En el uso del término contingencia propuesto por Vittorio Morfino que no se encuentra en el mismo Spinoza-, la contingencia es sinónimo de azar, es decir, de ausencia de finalismo o, en general, ausencia de un orden transcendente al discurrir de los acontecimientos que marcaría su destino. Aunque el concepto correspondiente de Spinoza es, más bien, el de Dios como causa inmanente de todas las cosas, respecto a él podemos decir lo mismo 
que explica Olivier Bloch para Demócrito: el «hasard qui est en même temps nécessité»:

Así, la génesis de las cosas, igual que la de los mundos, se produce exclusivamente por «azar» y «necesidad»: azar de los encuentros, que es azar en el sentido en que ningún plan, ninguna intención, nada que parezca finalidad, preside su producción -azar que es a la vez necesidad, ya que esta producción es enteramente determinada por el proceso mecánico de los choques, entrelazamientos, combinaciones y divisiones en las cuales entran los átomos en función de sus dimensiones, de sus formas, de su posición, de su movimiento y de la dirección de éste. (Bloch 1985, p. 40)

Dios qua causa inmanente de toda producción o el Azar es el Hecho de que, como decía Mallarmé, «un coup de dés jamais n'abolira le hasard» (2003, p. 203). El azar no puede destruir el azar. El azar es absolutamente necesario. No puede dejar de haber producción de encuentros y rupturas. Los encuentros o cosas singulares no pueden dejar de producir efectos mientras existen, pero pueden disolverse, dejar de existir. Lo que no puede dejar de existir es que la destrucción de un encuentro es la formación de otro, de la ruptura de una conexión nace una nueva concurrencia. No pueden dejar de existir encuentros. Los encuentros son rupturas continuadas, siempre en relación de afirmación y resistencia con respecto a aquello con lo que rompen. Cuando uno termina es porque otro comienza. Esa es la potencia infinita de la naturaleza. Infinita porque la producción de una diversidad de encuentros que son también rupturas no tiene límites. Los encuentros se producen azarosamente, esto es, Dios no determina desde fuera que deba producirse este encuentro o este otro. Determina, inmanentemente, que no puede dejar de haber encuentros de una manera o de otra, de infinitas maneras, «infinita infinitis modis», dice Spinoza (E 1P16). La multiplicidad de los encuentros es, así, una consecuencia de la causalidad inmanente de la sustancia y, por esa misma razón, no es una multiplicidad indeterminada, sino una multiplicidad de relaciones, una multiplicidad sobre y subdeterminada, por la que cada encuentro se define en relación con otros con los que rompe (Sainz Pezonaga 2014).

Conviene distinguir, entonces, entre contingencia como azar o ausencia de finalidad o como potencia infinita de la naturaleza, que no es el uso del término que realiza Spinoza, y contingencia como indeterminatio sive ignorantia. Y lo esencial para tener en cuenta es que la exclusión de la indeterminación en Spinoza es tanto un presupuesto para la expulsión del finalismo como una condición para la necesidad de la ignorancia.

Cuando hablamos de ignorancia, no nos referimos a un estado negativo. La ignorancia está necesariamente implicada en unas ideas inadecuadas 
determinadas necesariamente por otras. ${ }^{3}$ La necesidad de la ignorancia es la necesidad de cada idea inadecuada concreta. La oposición entender / ignorar tiene, entonces, que pensarse como la oposición entre ideas adecuadas e ideas inadecuadas, todas ellas modos de la sustancia bajo el atributo del pensamiento $\mathrm{y}$, por ello, entramadas en la red de interdeterminaciones necesarias de la naturaleza pensante.

De esta forma, el problema de la oposición entre necesidad y contingencia se resuelve en el conflicto entre las ideas activas y las pasivas. Las ideas inadecuadas son pasivas porque su construcción y sus consecuencias no se perciben con claridad y distinción, no porque no produzcan efectos. De ahí que el conflicto entre el entender y el ignorar sea factual, porque, aunque la idea verdadera es índice de sí misma y de la falsedad, no suprime lo que la idea falsa tiene de positivo (E 4P1). El conflicto entre el entender y el ignorar es histórico y, no obstante, la filosofía de Spinoza no es historicista. La verdad de una idea depende de su producción y constitución interna, no de la pugna en la que entra, necesariamente, con la falsedad de otras ideas. Entiéndase, el antagonismo con otras ideas es insoslayable y la comunicación de la idea verdadera y su composición con otras ideas verdaderas pasa a través del conflicto con la falsedad, pero no la define como tal. La verdad de la idea es su esencia. Y, como sobre todas las cosas singulares, sobre la idea verdadera cabe una mirada simultánea de doble alcance. Cuando contemplamos la idea desde el punto de vista de la necesidad o la naturaleza absoluta, la percibimos $s u b$ specie aeternitatis, y así conocemos su verdad o su esencia y perseverancia. Cuando la consideramos desde el punto de vista de su interdeterminación con otras ideas, conocemos su existencia y su determinación. Pero, la posibilidad misma de practicar sobre ella la doble mirada simultánea ya la caracteriza como verdadera. La inadecuación de la idea reside precisamente en que no podemos concebirla ni sub especie aeternitatis ni en su interdeterminación con otras ideas, ambos puntos de vista sólo pueden ir juntos. Una idea es inadecuada en tanto se resiste a ser considerada como idea integrada de ideas e integrante en ideas, cruce del que emerge la eternidad. Es lo que ocurre, por ejemplo, siempre que atribuimos existencia a las cosas que imaginamos tal como las imaginamos, sin tener en cuenta que la naturaleza de nuestro cuerpo está también implicada en esa imaginación (E 2P17 y E 2P18). La historicidad radical de Spinoza es una historicidad sin historicismo, un «racionalismo histórico», como lo llama Pierre-François Moreau (2003, p. 123), para el que todo, lo humano y lo no humano, es natural. Una historicidad en la que la

3 Para una exposición del modo en que el mismo Spinoza explica la formación imaginaria de las ideas de lo posible y lo contingente, $c f$. Morfino 2012, pp. 33-36. 
historia social es una parte real de la historia natural (Marx 1984, p. 153). ${ }^{4}$

El ser relacional de las cosas singulares depende tanto de una negación, su finitud, el que una cosa sea limitada o terminada por otra dentro del mismo atributo (E 1D2), como de una afirmación, su esencia, su conatus o potencia. Pero la negación de la finitud no es indeterminación, sino interdeterminación (A limita B y B limita A) englobada en una afirmación absoluta: infinita, única e indivisible. Siempre hay determinación. Siempre hay producción. Hay hacer-ser. Lo que hay se hace-ser. La naturaleza absoluta es causa sui. En la filosofía de Spinoza, la oposición entre necesidad y contingencia inicial se transforma en antagonismo entre acción y pasión, esto es, entre libertad y servidumbre. De este modo, Spinoza subvierte completamente la relación tradicional entre libertad, necesidad, contingencia y azar. La libertad humana queda del lado de la necesidad, la determinación y el azar. ${ }^{5}$ La servidumbre, del lado de la contingencia y la indeterminación.

En Spinoza, la historicidad radical de las cosas singulares es lo que define su singularidad: su diversidad, su relacionalidad múltiple, su irreductibilidad, su necesidad y su eternidad (Negri 2012, pp. 58-59). Es una conclusión crítica en la que el Dios de las religiones monoteístas y de las filosofías a ellas vinculadas queda enteramente desplazado. El Dios de Spinoza -la necesidad absoluta de la autoproducción de la totalidad, la naturaleza absoluta- es causa sui en el mismo sentido en que es causa de todas las cosas (E 1P25S). No hay, por tanto, creación ni separación entre Dios y las cosas singulares. Y cuanto más conocemos a éstas, más conocemos a Dios (E 5P24).

\section{ABOLICIÓN DE LA MONARQUíA ONTOLÓGICA}

Dios consta de infinitos atributos, dos de los cuales son el pensamiento y la materia. El universo material no es exterior a Dios, sino uno de sus infinitos atributos (E 1P14C2), una expresión de su esencia eterna e infinita, el hacerser absoluto expresado materialmente. Abolida la división jerárquica entre Dios y los seres singulares y entre el pensamiento y la materia, no hay cabida tampoco para concebir un Dios dotado de voluntad libre, que sólo podría consistir en un poder espiritual de actuar sobre una materia y unos espíritus separados y subalternos. Con estas dos supresiones, basta para anular la idea de Dios como legislador o como juez (Deleuze 2003, p. 134). Dios no es ya

4 «La historia no es un designio o un drama, sino pura facticidad del devenir de los encuentros de diferentes seres con diferentes potencias y conatus» (Espinosa Antón 2008, p. 40).

5 Hay un sentido de libertad negativa en la noción de azar cuando es entendida como ausencia de un destino que defina nuestras vidas, pero Spinoza está más interesado en la libertad positiva implicada en el conatus como expresión determinada de la potencia infinita de la naturaleza. 
un agente ético o político, como aclara el Apéndice a la Parte I de la Ética y reafirma E $2 \mathrm{P} 3 \mathrm{~S}$. Dios no pone normas. «Dios = causa inmanente de la totalidad infinita de los aconteceres $=$ hacer-ser absoluto de todos los hechos = producción de todas las producciones» es la verdad que destruye la ilusión de la indeterminación y, al tiempo, genera el espacio ético de la historicidad radical de los seres singulares, del conocimiento de la mente humana como conocimiento de «hechos» a partir de su conexión productiva con otros «hechos». El conocimiento de esta verdad y el amor intelectual de Dios (esto es, el amor que despierta la verdad de Dios = causa inmanente de todas las causas) son, entonces, la felicidad suprema de la mente.

La consecuencia política del desplazamiento de la idea de un Dios soberano y juez de los seres humanos es un concepto de religión sin sumisión. Si Dios no es un rey, no hay un Dios legítimo frente a otros pretendientes ilegítimos, no es necesario realizar ceremonias que muestren sumisión ante él, no hay que creer historias que sostengan la defensa de su legitimidad real, no hay que temer castigos ni esperar premios (TTP 4), su poder no es sobrenatural (TTP 6) y no tiene ministros en los que delegar su autoridad, más allá de los gobernantes de hecho. ${ }^{6}$ Estas son las consecuencias que Spinoza extrae de manera expresa en el Tratado teológico-político, en el que la transformación de la teología en ética y de la ética en democracia, despliega un recorrido completo (Tosel 1994, pp. 9-11). En la Ética, el desplazamiento de la idea del Dios soberano y juez viene de la mano de la imposibilidad de atribuir a Dios una voluntad libre, en la que se enreda el juego de espejos (Montag 2005, pp. 62-63) entre el hombre y Dios y los reyes y Dios (E 2P3S). La idea de voluntad libre es la superficie que refleja alternadamente las figuras de Dios, el hombre y el rey.

Según François Zurabichvili, de entre los filósofos cristianos sólo Descartes habría asimilado de manera global la potencia divina y la potencia del monarca. Otros, como Tomás de Aquino, Hobbes o Leibniz, la esquivarían de una u otra forma, o la aceptarían sólo parcialmente (2002, pp. 191192). Respecto a Aquino, Zourabichvili tiene razón en la medida en que su pensamiento no admite una analogía que vaya del hombre a Dios, aunque sí la que va de Dios al hombre y al rey. En ningún caso puede aceptar a Dios como imagen del hombre. Sin embargo, es Tomás de Aquino quien trabaja en La monarquía con un paralelismo analógico entre Dios, el hombre y el rey (Aquino 1989, p. 64).

Spinoza criticaría a Aquino no en tanto que éste expresamente atribuya a Dios una similitud con los reyes, sino en tanto que lo hace implícitamente. Sólo porque el Dios de Aquino es ya un Dios soberano, puede comparar al

6 TTP 19: 231, así como TTP 4: 62-64, TTP 6: 81 y TTP 13: 172.

Contrastes vol. XXVI-Nº1 (2021) 
rey con Él, por intermedio de la razón, que ha sido dotada también de poderes soberanos. ${ }^{7}$ Para Tomás de Aquino, el rey se asemeja a Dios, porque, diría Spinoza, Dios ha sido ya pensado a semejanza del rey. Para Spinoza, sin embargo, ni Dios es un rey, ni la razón es un rey, ni siquiera el rey es un «rey», ya que como dice en el Tratado político, la monarquía es, en realidad, una aristocracia encubierta (TP 6/5).

Dios no es un rey y los reyes tampoco son dioses. François Zourabichvili ha seguido con atención en Le conservatisme paradoxal de Spinoza la crítica de éste a la divinización de los reyes ligada al rechazo de la monarquía absoluta. La figura paradigmática de la monarquía absoluta es, a juicio de Zourabichvili, Luis XIV de Francia, el «Rey Sol», contemporáneo de Spinoza. En el TTP hay dos pasajes en los que Spinoza expresa el peligro de la divinización de los reyes. El primero es TTP Pr:7 en el que atribuye al uso que la monarquía hace de la religión el que los hombres combatan por su servidumbre como si fuera su salvación. El segundo es TTP 17: 204-205, donde Spinoza pone algunos ejemplos históricos: los reyes persas, Alejandro, Augusto; y específica el uso político de la religión por parte de los monarcas como medio para ser reconocidos como superiores y hacer depender su mandato de designios sobrenaturales y no del consentimiento de sus semejantes.

En el TP, la crítica a la divinización de los dioses se encuentra en los capítulos VI y VII. Zourabichvili la resume en cinco «quimeras». La primera ya la he apuntado. El rey nunca gobierna en solitario, por lo que la monarquía es en realidad una aristocracia encubierta. La segunda es el sueño tiránico de que el rey puede transformar la naturaleza y hacer que los hombres se plieguen a sus deseos hasta dejar de ser hombres. La tercera es la confusión entre el capricho del rey y la ley. La ley exige una constancia que no puede descansar en la variabilidad de la opinión de una persona. La cuarta es la eternidad del rey. La realidad es que el rey muere y otra persona debe ocupar el trono, lo cual suspende la institución monárquica, dejando ver que su continuidad depende siempre de la multitud. La quinta y última es concebir que la solución a los problemas que genera el hecho de que el monarca sea una persona, se resuelve haciendo que el rey sea un dios o Dios, como en la teocracia. Que el rey tenga que ser un dios conlleva el giro de pensar que la monarquía es en sí misma una quimera, ya que solo un ser suprahumano podría dirigirla (Zourabichvili 2002, cap. 7). De ahí, la simetría entre la creencia en el Dios soberano y la divinización de los reyes. Pensar a Dios como soberano supone hacer de Dios un modo finito. Pensar al rey como un dios implica convertir al rey finito en una sustancia. Mantener con claridad la distinción y la relación entre la sustancia y los modos finitos es la clave de las distinciones metafísicas

7 Siguiendo en ello a Platón (República, 441e) y Aristóteles (Política, 1254b). 
u ontológicas de Spinoza que impide toda sacralización de los gobernantes y conduce a pensar la política desde la potencia de la multitud y, con ella, a la multitud libre (Ibid., cap. 8).

En La anomalía salvaje (1981), Antonio Negri teoriza precisamente esta asimetría entre la potencia inmanente de la multitud y el poder legitimado como expresión de una voluntad libre en un juego de espejos, en el que las figuras de Dios, el individuo y el monarca se reflejan las unas en las otras, y la potencia inmanente de la multitud como antagonismo entre la potentia y la potestas. La potentia es la productividad del ser que se expresa colectivamente en la multitud. La potestas es todo intento de someter esa productividad, esa potencia constitutiva a un orden jerárquico o a una unidad transcendente, de la que la monarquía es una figura paradigmática, como habían propuesto Jean Bodin y Thomas Hobbes. De hecho, para el primero, toda forma de gobierno es lógicamente monárquica, porque la soberanía es precisamente la reducción a uno (monarca, aristocracia, pueblo) de la multiplicidad productiva (Negri 2012, p. 34). Negri plantea que, en el Tratado teológico-político, Spinoza descubre que la potestas y su juego de espejos es también creación de la potentia de la multitud (Negri 2006, pp. 128-139). Se presentan, así, dos concepciones de la política irreconciliables: o bien todo régimen político se sostiene sobre una lógica monárquica o bien todo imperium se define por la potencia de la multitud, es decir, la democracia es la estructura de toda forma de gobierno (Ibid., p. 381-382). Pero las dos posiciones no son simétricas. El fundamento monárquico realmente efectivo descansa en un juego de espejos vacío cuya realidad proviene de la capacidad constitutiva de una imaginación colectiva que desconoce su propia potencia. La productividad democrática es, en última instancia, la fuente tanto de su liberación como de su propia denegación, subordinación o mistificación. La servidumbre es liberación truncada o bloqueada. La multitud sierva proviene del fracaso o de la derrota de la multitud libre, pero ésta nunca desaparece del todo porque sin ella tampoco hay sociedad. O, como dice Negri, la potentia siempre excede a la potestas, porque la potestas requiere de la potentia para existir, pero no al revés (2012, pp. 14-19).

La multitud, red abierta de relaciones, de correlaciones, está constituida por una pluralidad indefinida de historias singulares, de procesos de liberación y de servidumbre, que, en su concurrir y oponerse, la dotan de un determinado poder de actuar, de una determinada historia singular.

La abolición de la monarquía ontológica va, entonces, ligada, es inseparable, diría, en Spinoza a una propuesta de filosofía política de carácter democrático. No parece, por ello, lógico pedirle al Spinoza de la Parte I de 
la $E$ tica ${ }^{8}$ que deduzca cada cosa singular a partir de la sustancia, bajando por los atributos, siguiendo por los modos infinitos, etc. Por el contrario, cada cosa singular se deduce de aquellas otras cosas singulares que son causa de su existencia y que la determinan a obrar, no de la sustancia (Macherey 1990, p. 180). De la sustancia se deduce que cada determinación singular es absolutamente necesaria y nada más. Si existe, es porque es causada necesariamente por la relación entre sus partes. Y si persevera en la existencia, es porque necesariamente nada la determina a dejar de existir. De esa manera, y de modo rotundo, Spinoza demuestra que es imposible pensar que haya algo más allá de la trama infinita de las interdeterminaciones singulares.

\section{SER ES SER CAUSA}

Esta concepción de la realidad de las cosas nos lleva a otra cuestión básica para entender la Ética de Spinoza y el modo en que supera los problemas con los que se encuentra en el Tratado Breve. Y es que, en la Ética, Spinoza va a defender que nunca se conoce nada como efecto únicamente. Conocer verdaderamente una cosa, dice Spinoza, equivale a conocer el modo en que se relacionan activamente las partes que la componen. Y cuando conocemos la naturaleza de la cosa, conocemos, a partir de ella, su potencia: lo que se sigue de esa naturaleza. Conocemos una cosa singular como efecto cuando conocemos su naturaleza compleja. Pero, al conocer su naturaleza, la conocemos inmediatamente como causa, pues de ella se siguen necesariamente efectos. Nunca conocemos verdaderamente puros y simples efectos. El conocimiento de los efectos es un conocimiento simultáneo de causas. Conocer verdaderamente una cosa es conocerla como causa, pero no como causa transitiva, sino como causa inmanente, esto es, como causa entre causas, causa recíproca dentro del doble nivel de complejidad. La relacionalidad múltiple es una relacionalidad causal, una relación de interdeterminación.

Detrás de esta primacía de la causa está el principio spinoziano de causa sive ratio. Spinoza identifica las propiedades de una cosa con los efectos que causa. E identifica la consecuencia lógica con el efecto causal. Dentro de una cadena de deducciones lógicas, los enunciados funcionan como conclusiones y como premisas de un nuevo argumento. La deducción que se desplaza de las premisas a las conclusiones se mueve simultáneamente en un despliegue que procede de las causas a los efectos dentro de una doble trama de causalidad inmanente. Spinoza había dicho en el Tratado de la reforma del entendimiento,

8 Aunque sí lo sería pedírselo al Spinoza del Tratado Breve. En esta obra temprana hay, efectivamente, además de una referencia a la causa emanativa (KV I, III, 2), una concatenación descendente entre la naturaleza naturante y la naturada, así como una relación causal entre los modos universales y particulares que componen esta última, $c f$. KV I, VIII y IX. 
$\S 85$, que la idea verdadera revela cómo y por qué algo se hace o fue hecho $\mathrm{y}$, por ello, la ciencia verdadera procede de la causa a los efectos (Macherey 1990, pp. 70-71).

La concepción de la naturaleza de las cosas como causalidad necesaria, la identificación de esencia y potencia, rige en toda la Ética, en toda la obra política, y también en lo que Spinoza entiende por «ética»: «el conocimiento de la mente humana y de su suprema felicidad» (E 2Pr) o, de otro modo, el esfuerzo por hacer dominante una concepción de nosotros mismos como causas a un tiempo adecuadas y parciales absolutamente necesarias.

Llevado al conocimiento de nosotros mismos, esa identificación significa que nunca podemos conocernos verdaderamente sólo como efectos. Si nos conocemos, lo hacemos simultáneamente como efectos, como causas adecuadas y como causas parciales. Pero, hay más, para Spinoza ser pasivo no significa en absoluto ser efecto. Ser pasivo en Spinoza es ser causa, ser causa parcial. Esta es la consecuencia que se sigue de la necesidad absoluta de la naturaleza. En ningún momento, tiene cabida pensarnos con verdad en Spinoza como efectos puros: al revés, somos causas. Todo lo que es, es productivo, es efectivo, genera efectos necesariamente. Absoluta necesidad y absoluta efectividad coinciden.

Entiendo, entonces, desde aquí, que la pasividad absoluta no puede pensarse desde la filosofía de Spinoza. La pasividad absoluta sólo puede pensarse desde una filosofía que deje espacio para la indeterminación ontológica. Y la indeterminación ontológica sólo puede pensarse, a su vez, desde una problemática que acepte una pluralidad de sustancias. Si hay seres que pueden no actuar, en términos absolutos, es porque pueden aislarse perfectamente de lo que les rodea, porque son sustancias entre sustancias (en el sentido tomista y cartesiano que recibe Spinoza). Ser sustancia en este sentido no implica efectividad. Implica que la efectividad puede ser o no ser, deja un espacio de indeterminación en el que caben la actividad absoluta o la pasividad absoluta. Ese es el hueco que requiere la creencia en la voluntad libre y el hueco, por tanto, que ocluye la filosofía de Spinoza.

La necesidad absoluta de la interdeterminación, sin embargo, es necesidad absoluta de la efectividad. Ser es ser causa. Es imprescindible pensar el determinismo de Spinoza, el interdeterminismo, diríamos mejor, como algo completamente distinto de un mecanismo ante el que sólo cabe una conciencia meramente espectadora, contemplativa.

Para poder existir, una conciencia espectadora tendría que poder quedarse fuera de la urdimbre infinita de interdeterminaciones. Pero, el determinismo activo de Spinoza consiste en saber que somos necesariamente causas y que no podemos dejar de ser causas. Y que nada existe fuera de la interdeterminación absolutamente necesaria de todas las causas. Que «contemplar», si se 
quiere, «teorizar», «entender» (intelligere) es también, por tanto, ser causa: hay una red infinita de interdeterminaciones de pensamiento en la que está integrada necesariamente cualquier idea singular. También la teoría de la interdeterminación infinita de E 1P28.

Cuando el determinismo se concibe como el negativo de la voluntad libre, sin más especificación, la única imagen que podemos hacernos de nosotros mismos es la de puros efectos. El determinismo pasivo, el determinismo contemplativo, el determinismo imaginario, como se quiera llamar, sigue atrapado en la idea inadecuada de que únicamente podemos ser causa si existimos sin las demás cosas. Para él, nuestra causalidad sólo podría generarse desde el encapsulamiento que presupone la voluntad libre.

Ahora bien, el determinismo activo de Spinoza responde a una problemática completamente diferente, a una concepción de la necesidad radicalmente distinta de la que funciona en las doctrinas de la voluntad libre. Es tan dispar que lo que el determinismo activo afirma justamente como imposible es que seamos únicamente efectos. Lo que el determinismo activo de Spinoza afirma como imposible es que podamos existir y al mismo tiempo no ser causas entre causas. Eso, efectivamente, según el determinismo activo de Spinoza, no lo podemos elegir. Es más tampoco podemos elegir ser una causa de menor potencia (E 4P20S). No podemos elegir la tristeza, ni el odio. Desde toda la eternidad, hemos decidido ser alegres y amar. Esta es nuestra determinación. Esto somos. Lo que nos mueve a actuar es siempre nuestra lucha por estar alegres y amar, ${ }^{9}$ nuestro conatus, nuestro poder seguir siendo causas, nuestra esencia, nuestra absoluta necesidad.

\section{CONCLUSIÓN: LA CAUSALIDAD INMANENTE DE LOS SERES SINGULARES}

A las teorías de la interdeterminación y de la necesidad de Spinoza va unido de modo indisoluble un no menos original concepto de causalidad, que se funde con su concepto de libertad. Spinoza entiende la causalidad siempre, tanto para Dios como para las cosas singulares, como causalidad inmanente; la segunda, sin embargo, ha sido menos atendida que la primera. La noción de causalidad inmanente para las cosas singulares la encontramos en la definición 7 de la Parte II. Se halla también en el segundo axioma 1 de la «física de los cuerpos», la sección de la misma Parte II que sigue a la proposición 13, en E 2P24D y en la carta 32 a Oldenburg.

Lo importante de la causalidad inmanente de las cosas singulares es la forma en la que éstas se unen. Las cosas singulares se unen concurriendo a una misma acción, se unen como causas (en esta tesis, podríamos decir, descansan enteras la ética y la política de Spinoza). Y cada cosa finita es resultado de la

9 E 3P12, E 3P13 y E 3P13C. 
unión de otras cosas finitas. El efecto es, entonces, aquello que se sigue de una unión determinada de cosas (E 2D7). Con ese efecto, a su vez, la unión de cosas se unirá a otras causas en una acción y será causa parcial de un nuevo efecto y así hasta el infinito. La conexión infinita de las cosas finitas de la que habla E 1P28 es, por tanto, una unión infinita de causas. Según Spinoza toda unión ha de pensarse como interdeterminación, como encuentro que tiene su propia ley, en el que se da una determinada forma de relación entre sus componentes. La interdeterminación no es un principio que gobierne extrinsecamente la urdimbre infinita de causas, sino que la interdeterminación articula intrínsecamente a cada cosa singular.

Para poder pensar la causalidad como inmanente no puede haber nada que pueda concebirse sólo como efecto o como puramente pasivo, al modo en que Descartes concibe la materia, criticado duramente por Spinoza en la carta 81 a Tschirnhaus (Ep 81: 332).

El ejemplo más problemático y más simple de la causalidad inmanente de las cosas singulares que podemos encontrar lo expone Balibar en «Individualité et transindividualité chez Spinoza» (2018, p. 208). Lo simplificaré todavía más. Es el más problemático porque es el mismo que Spinoza presenta, justo antes del segundo axioma 1 de la «física de los cuerpos», para enunciar su principio de inercia y que, en su pluma, parece ser un ejemplo más bien de todo lo contrario de lo que quiero ejemplificar, parece ser un ejemplo de causalidad transitiva. Se trata de mostrar que no es tal.

El ejemplo simple es este. A es un cuerpo en movimiento y B es un cuerpo en reposo. A golpea a $\mathrm{B}$ y hace que $\mathrm{B}$ pase de estar en reposo a estar en movimiento. La causa inmanente del paso del reposo al movimiento de $\mathrm{B}$ no es únicamente A, sino el encuentro entre A y B. Ese encuentro ha producido un nuevo individuo $\mathrm{AB}$ del cual se sigue el movimiento determinado de $\mathrm{B}$. Visto así, el encuentro de $\mathrm{A}$ y de $\mathrm{B}$ produce y constituye el individuo AB. Éste es efecto de ambos, de A y de B. Y es la causa que produce que B pase del reposo al movimiento.

Pondré otro ejemplo, esta vez más cercano. Cuando nosotros hablamos y otras personas nos escuchan, no somos la causa única de la voz que esas personas están escuchando. Sin el aire como medio que transmite las ondas sonoras que producen nuestras cuerdas vocales y nuestra modulación bucal, sin el aparato auditivo de las otras personas que trasforma la energía mecánica de las ondas en señales electroquímicas que envía al cerebro, sin toda la complejidad de su cerebro, formada a lo largo de los años, que «interpreta», digámoslo así, esas señales, no se produciría el efecto de «escucha» que se está dando en nuestros interlocutores. Nuestra voz es causa parcial. Ella más el aire, junto al aparato auditivo y los cerebros de todos los que intervenimos en la situación, etc. conforman en relación activa los unos con los otros la 
causa adecuada o inmanente, la cosa singular, de la que se sigue el efecto de escucha que digo se da en las personas a las que nos dirigimos.

Fijémonos en cómo funciona aquí el concepto de necesidad. Porque, la necesidad de ese individuo compuesto que se forma cuando un conjunto de causas parciales coopera en la producción de un solo efecto no es algo que obstaculice la acción del individuo, sino que la necesidad es intrínseca a la misma acción del individuo. Diremos también que la necesidad es la esencia o el conatus de ese individuo.

La clave de la causalidad inmanente es que toda acción causal debe concebirse desde el doble nivel de complejidad. No es simplemente un efecto de conjunto en el que intervienen factores heterogéneos, como a veces suele traducirse. Es, más bien, una doble perspectiva sobre toda acción causal. Todo factor singular debe entenderse como causa parcial dentro de un efecto de conjunto y, al mismo tiempo, como causa adecuada de su propia intervención.

Pero, y en este mar de conexiones causales, nos podemos preguntar, ¿dónde estamos nosotros, nuestro cuerpo, nuestra subjetividad?

En principio, nuestro punto de partida es que sabemos que somos causas parciales, como todas las demás cosas singulares. Ahora bien, ¿qué consecuencias trae saberse causa parcial? Conocerse como causa parcial, si ese conocimiento es lo suficientemente potente, lleva a investigar las restantes causas parciales y a desear saber cómo nos afecta esa conexión con otras causas.

Lleva a sabernos igualmente causas adecuadas en cuanto, si podemos ser causas parciales, es porque nosotros somos producidos y constituidos también por una unión de causas parciales. Esa unión es nuestra naturaleza, nuestro conatus y de ella se sigue necesariamente algún efecto, por el que somos causa parcial.

Para Spinoza este es el punto de partida ineludible. Sabernos a un tiempo causas parciales y causas adecuadas. Saber que lo que nos mueve a actuar es siempre nuestro conatus. En una lógica circular, somos causa adecuada cuando proyectamos una mirada de doble alcance sobre nosotros mismos, cuando nos conocemos como causa adecuada y como causa parcial (E 4C1 y E 4C2). Éste es el punto de apoyo que sostiene un ciclo de liberación opuesto al ciclo de servidumbre en el que está enredada la creencia en la voluntad libre. Y la ética (E 2Pr) es en Spinoza una lucha contra la creencia en la libre determinación de la mente. Conocer la mente es, precisamente, saber que es efecto, saber que es causa adecuada y parcial. En este sentido, la ética de Spinoza es una ética contra la ignorancia activa respecto a la mente, esto es, contra la creencia en la voluntad libre como facultad de elección.

El ciclo de liberación consiste en que considerar nuestra capacidad de actuar (saber que somos causas adecuadas y parciales) aumenta esa misma 
capacidad. Y cuanto con mayor especificidad somos capaces de explicar esa trama de causas, esa múltiple relación que nos constituye y en la que estamos inmersos, en mayor medida consideramos nuestra potencia y en mayor medida ésta aumenta. La consecuencia es un deseo de entender (cupiditas intelligendi) más y mejor que se alimenta de sus propios efectos y que acompaña a todos los deseos activos, a todas las formas de la libertad humana (Matheron 1988, chap. VII y Quatrième Partie y Tosel 2008, pp. 109-110 y 173-175).

El ciclo de servidumbre consiste en que imaginarnos aislados de las demás cosas, como ocurre paradigmáticamente en la creencia en la voluntad libre, también nos produce alegría, esto es, aumenta nuestra capacidad de actuar. La razón es que nos permite distinguirnos imaginariamente del resto de los demás seres. Pero la consecuencia que se sigue de esa alegría es un deseo de continuar imaginándonos aislados, esto es, un deseo de ignorancia que bloquea el aumento de potencia ganado en un primer momento.

La pugna entre ambos ciclos no tiene fin. En esto es tajante Spinoza: «el hombre está sujeto (obnoxium) siempre, necesariamente, a las pasiones» (E 4P4C). Nunca podremos eliminar completamente la idea inadecuada que obstaculiza con mayor fuerza el proceso de conocimiento: el finalismo o, su otra cara, la creencia en la voluntad libre. Pero tampoco es posible abandonar la lucha ni elegir bando.

\section{REFERENCIAS BIBLIOGRÁFICAS}

BALIBAR, E. 2018: Spinoza politique. Le transindividuel. París: PUF. AQUINO, T. 1989: La monarquía. Madrid: Tecnos.

ARISTÓTELES 1988: Política. Madrid: Gredos.

BLOCH, O. 1985: Le Matérialisme. París: PUF.

DELEUZE, G. 2003: Spinoza : Philosophie pratique. París : Les Editions de Minuit. ESPINOSA ANTÓN, F. J. 2008: «Metafísica y concepción de la historia en Spinoza», en J. Carvajal y M. L. de la Cámara (coord.). Spinoza: de la física a la historia. Cuenca: Ediciones UCLM.

FERNÁNDEZ GARCÍA, E. 1997: «Necesidad libre, libertad necesaria. E. Giancotti in memoriam». En La encrucijada de los afectos. Ensayos spinozistas. Cuenca: Ediciones de la Universidad de Castilla-La Mancha, 2018, pp. 121-151

LACLAU, E. 2000: Nuevas reflexiones sobre la revolución de nuestro tiempo. Buenos Aires: Nueva Visión.

MACHEREY, P. 1990: Hegel ou Spinoza. París: La Découverte.

MACHEREY, P. 1998: Introduction à l'Éthique de Spinoza. La première partie. La nature des choses. París: PUF.

MACHEREY, P. 2011: De Canguilhem a Foucault: la fuerza de las normas. Buenos Aires: Amorrortu.

MALLARMÉ, S. 2003: Poesías. Madrid: Hiperión. 
MARX, K. 1984: Manuscritos: economía y filosofía. Madrid: Alianza Editorial.

MATHERON, A. 1988: Individu et communauté chez Spinoza. París: Minuit,

MONTAG, W., 2005: Cuerpos, masas, poder. Spinoza y sus contemporáneos. Ciempozuelos: Tierradenadie ediciones.

MOREAU, P.-F. 2003: Spinoza et le spinozisme. París: PUF.

MORFINO, V. 2012: «Spinoza y la contingencia». En D. Tatián (comp.), Spinoza. Octavo Coloquio. Córdoba: Brujas, pp. 23-39.

NEGRI, A. 2006: Spinoza. Roma: DeriveApprodi.

NEGRI, A. 2012: Spinoza e noi. Milán: Mimesis.

PLATÓN 1986: Diálogos IV. República. Madrid: Gredos.

SAINZ PEZONAGA, A. 2014: «Mil Fisuras. Arte y Ruptura a partir de Althusser», Décalages. Vol. 1: Iss. 1. http://scholar.oxy.edu/decalages/vol1/ iss $1 / 1$

SPINOZA, B. de 1972: Opera (4 vols.). Ed. de C. Gebhardt. Heidelberg: Carl Winters ( $1^{\mathrm{a}}$ edición, 1925).

SPINOZA, B. de 1980: Ética. Madrid: Editora Nacional.

TOSEL, A. 1994: Du matérialisme de Spinoza. París: Kimé.

TOSEL, A. 2008: Spinoza ou l'autre (in)finitude. París: L'Harmattan.

ZOURABICHVILI, F. 2002: Le conservatisme paradoxal de Spinoza. Enfance et royauté. París: PUF.

Aurelio Sainz Pezonaga es Profesor Asociado de Filosofía en la Facultad de Ciencias de la Educación y Humanidades de Cuenca (UCLM)

Lineas de Investigación:

Ética y política, Arte y política, Spinoza y la filosofía moderna, materialismo, marxismo y neomarxismo

Publicaciones recientes:

(2020): «Reciprocidad y utilidad común en la filosofía política de Spinoza», Ágora: papeles de filosofía 40(1), pp. 207-228.

(2019): «Multitud libre y producción del deseo común en Spinoza» Araucaria. Reivsta Iberoamericana de Filosofía, Política, Humanidades y Relaciones Internacionales 21. pp. 23-44.

Correo electrónico: Aurelio.Sainz@uclm.es 